\title{
Psychometric Characteristic of Social Competence and Behaviour Evaluation (SCBE-30) in a Sample of Nigerian Preschoolers
}

\author{
| Adetunji, A. A ${ }^{1, *} \mid$ Aliu, A. $\mathbf{H}^{2}$ | Salami, T. A $^{3}$ |
}

1,2 Departement of Statistics, Federal Polytechnic, Ile-Oluji, Nigeria

${ }^{3}$ Departement of Mathematics / Statistics, Osun State College of Technology, Esa-Oke, Nigeria

*adecap4u@yahoo.com

\begin{abstract}
Social Competence and Behaviour Evaluation (SCBE-30) is a 3 factor (Externalizing, Internalizing and Social Competence) 30 item questionnaire that examines Preschoolers (Kindergarten and Nursery). The main goal of this study is the validation and adaptation of the scale in Nigeria. 400 pre-schoolers in Ile-Oluji, Ondo State, Nigeria are involved in the study while 364 children whose Parental Consent Form was obtained are the final participants. McDonald's wt (McDonald, 1999) measure of reliability using the psych package from CRAN (Revelle, 2008) was used to verify the internal consistency of the scale. The original subscale with 10 items of the novel SCBE-30 version is not confirmed by the confirmatory factor analysis. Seven items showed significant contribution to both SC and AW while all 10 items of the AA subscale have significant loadings. However, only 4 items for the SC scale showed factor loading of above 0.40, 3 for $A W$ and 6 for $A A$. Exploratory factor analysis showed that boys are more aggressive than girls while girls exhibit more social competence and internalizing behaviour. The social competence scale is found to be significantly different from other factors while both Anger-Aggression and Anxiety-Withdrawal showed no difference. All inter-factor correlations agreed with the literature. Five models are compared using various modifications and the final accepted model have Chi-Square $=261.316 ; \mathrm{GFI}=0.946, \mathrm{CFI}$ $=0.953, R M S E A=0.027$ and $S R M R=0.047$. The new 24-item scale for the Nigerian sample shows good psychometric characteristics and meets validation criteria as reported by researchers where the scale had been earlier validated.

KEYWORDS

SCBE30; anxiety; withdrawal; anger; aggression; social competence; Fit-Indices
\end{abstract}

\section{INTRODUCTION}

Challenges facing pupils in preschool (an educational institution for children too young for elementary/primary school) are quite enormous. Various government educational policies in Nigeria in particular and Africa at large do not give the necessary attention to the plight of these preschoolers. Hence, the increase in social disorder among Nigerian youths through various social vices is fast becoming a threat to the existence of the country. Emotional disorder records for preschoolers are on the increasing side, especially in the last few decades (Lavigne et al, 1999). If proper attention had been given to the youths earlier in life, various attributes that indicate mental health disorderliness (like being destructive and signs of exteriorization-hyperactivity, oppositional defiance, and antisocial behaviours) would have been identified (Poissant, 2000) and corrective measures would have been taken. Records from the United States showed that a huge amount of money is 
being spent yearly for maintaining mental disorders in children and adolescents when earlier prevention and diagnosis would have required less significant intervention (Richardson, Keller, Selby-Harrington and Parrish, 1996).

In Nigeria, challenges of governance are so numerous that little or no attention is given to societal maladaptation. Policies are changed at almost every change of government. These among others had worsened the quality of life of children in particular and the total populace at large.

Pupils with internalization disorders like anxiety, depression, antisocialism, etc. usually go unnoticed in society and most often do not receive the required attention. Also, those with capabilities of being socially effective with different traits of leadership are often neglected and the essential developmental programmes to equip them for their abilities are usually non-existence.

Studies on social competence did not begin until the early 20th century. Then, it was associated to mental disorderliness, thereby increasing research on the interaction of children in their social activities (Dodge et al. 1989). Mastering social skills and interpersonal interactions develop over time from infancy to adolescence and this builds on knowledge and skills previously learned (Semrud-Clikeman, 2007). In a social setup, social competence involves being able to easily get along with other people. It majorly focuses on interpersonal skills i.e. ability to interact positively among people. Prosocial skills (like friendliness and helpful behaviours) and self-control skills (like problemsolving and anger management) are among various markers of social competence (Semrud-Clikeman, 2007). Voeller (1994) listed three clusters of problem behaviours that impair social competence as (i) hostile and aggressive group (ii) a perceptual subgroup with discrepancies, and (iii) a group with challenges in self-regulation. Children that belong to hostile and aggressive groups often act out behaviours that negatively affect their ability to relate and sustain interactions among peers. They tend to apply wrong problemsolving techniques to social challenges (Crick \& Dodge, 1994). Children that have perceptual deficits show difficulty in social cues by their facial expression and body gestures while those self-regulation deficits tend to have the classic difficulties in executive functions (Crick \& Dodge, 1994). Social competence is interconnected with other areas of child development like emotion self-control and attention control (Blandon et al., 2010). The ability of any child to interact with other children affects all aspects of his/her development and maybe "the single best childhood predictor of adult adaptation," opined Hartup (1992). Social interactions make the children feel confident and acceptable. This in turn improves their self-belief and self-assurance.

For preschoolers, prosocial activities include the ability to engage with their peers while being separated from their parents. Since they are just learning to coordinate their social behaviour, social interactions are usually brief and characterised by recurrent disagreements. Friendships are less established when compared to other developmental stages of life. At this stage, children are focused on peer acceptability while boys are usually characterised with rough. A lot of studies had been conducted on assessing the social competence of children at different stages of life with different assessment tools. However, few reports of the African perspective (especially Nigeria) have been reported on both internalization and externalization disorders among preschoolers (kindergarten and nursery). 


\section{RESEARCH METHODS}

\section{Research Instrument}

The Social Competence and Behaviour Evaluation (SCBE) was designed by LaFreniere et al., (1992) to evaluate the expression and emotional regulation, adjustment to difficulties and prosocial patterns in children aged $2 \frac{1}{2}$ years to $6 \frac{1}{2}$ years. The preschoolers in this Nigeria sample were in kindergarten and nursery classes with ages ranging from 2 years (24 months) to 5 years (60 months).

The primary focus of the SCBE scale was to evaluate social behaviour at school from the teacher's perspective. The scale provides a generally acceptable behavioural description that is objective, valid, easy to administer and interpret with a focus on the presence or absence of maladaptive and adaptive behaviour among preschoolers (Zupanic et al., 2000). The instrument allows researchers to highlight a child's specific vulnerabilities and competencies.

A multinational study (LaFreniere et al., 2002) presented a compelling and concise case for the universality in the way SCBE is structured using 4640 preschoolers from 8 different countries (Austria, Russia, Brazil, Italy, Canada, Japan, China, and the United States).

SCBE-80 (an eighty item instrument) was designed with the purpose of providing a standardized description of valid and reliable behaviour for preschool teachers. The SCBE80 has 8 basic scales (Angry-Tolerant, Depressive-Joyful, Oppositional-Cooperative, Anxious-Secure, Isolated-Integrated, Egotistical-Prosocial, Aggressive-Calm, DependentAutonomous) and 4 composite factor scales (Internalizing Problems, Social Competence, General Adaptation, Externalizing Problems). Each basic scale consists of 10-items (brief statements that describes a child behaviour on the rating of 1 - Never; 2 - Very rarely; ...; 6 - Always (Likert Scale). Five items in each basic scale describe positive adjustment and the other five indicate adjustment difficulties (Dumas et al., 1997; LaFreniere \& Dumas, 1996a). In order to assess affective and behavioural problems worldwide, SCBE-80 differentiates specific subtypes of maladaptive and adaptive factors of preschoolers. Principal component analysis of various researches using the SCBE-80 have repeatedly and consistently identified 3 factors samples: Anger-Aggression, Anxiety-Withdrawal, and Social Competence (Dumas et al., 1997; Dumas et al., 1998; and LaFreniere \& Dumas, 1996b). Among these studies, SCBE-80 had shown internal consistency evaluated by Cronbach's alpha (Cronbach, 1951) reliability test ranging from 0.79 to 0.91 and inter-rater reliability of between 0.72 and 0.89 for all scales. This 3-factor sample is composed of a 30-item scale with 3 subscales (Anxiety-Withdrawal, Social Competence, and AngerAggression), each having 10 items on a 6 point Likert scale (Never-1 to Always-6) with highly similar psychometric properties is called the SCBE-30. The Social Competence subscale has 10 items that show positive interpersonal relationships and social interactions with a high score in tolerance cooperativeness, autonomy, calmness and security. The Anger-Aggression subscale also has 10 items that describe various oppositional and externalizing behaviours like anger, egoistical, and aggression, while the AnxietyWithdrawal subscale consists of 10 items that evaluate various isolated, dependent, and internalizing behaviours such as depression, anxiety, isolation, shy and spending more time alone. Children with lower social competence tends to have more behavioural problems and poor academic performance compared to those who are more competent (Malti, 2006; and Bollen, 1989). SCBE 30 had shown a very positive consistency in various countries where it had been validated, in the US (LaFreniere \& Dumas, 1996b) and Quebec, Canada (Dumas, et al., 1997) validations, all its 30 items load more than 0.40 in exploratory factor analysis. For Brazil validation (Bigras \& Dessen, 2002), only an item has loading less than 
0.40 while more items loaded more than 0.40 in the Russian validation with 3 items among the externalizing behaviour showing cross-loading (Butovskaya \& Demianovitsch, 2002).

\section{Methods}

26 teachers (23 females and 3 males) and 8 assistant teachers (all females) across five schools completed the SCBE-30 for 364 children. Table 1 presents the frequency of the age and gender of the evaluated children in a cross-tabulation.

Table 1. Age/Gender cross-tabulation of the evaluated children

\begin{tabular}{l|l||l|l|l|l||l}
\hline \hline \multicolumn{2}{c||}{} & \multicolumn{4}{|l||}{ Age (years) } & \\
\cline { 3 - 7 } \multicolumn{2}{c|}{} & 2 yrs & 3 yrs & 4 yrs & 5 yrs & Total \\
\hline \multirow{2}{*}{ Gender } & Male & 22 & 62 & 72 & 21 & 177 \\
\cline { 2 - 7 } & Female & 33 & 47 & 74 & 33 & 187 \\
\hline \hline & Total & 55 & 109 & 146 & 54 & 364 \\
\hline \hline
\end{tabular}

Parental Consent Form was sent to the parents with a brief explanation of the evaluation and the teachers were advised to leave out any child whose parent refuses to sign the form from the evaluation.

The schools' administrators avail the researcher with the opportunity of meeting with the teachers and familiarizing them with the purpose of the research. This was done at each school during the long break period in order not to disturb the academic activities in the schools. Teachers were introduced to the SCBE-30 form and detailed explanations were made on each of the 30 items along with the Likert scale rating system. A week was given to each teacher after which the researcher went back with several copies of the form based on the number of parental consent forms received. Teachers were given two weeks to assess and evaluate the pupils (each of the teachers had been in charge of the class for at least a term of about three months). They were advised to use the class register to select each pupil (each form had been numbered based on the number of children to be evaluated in each class). This measure helped in ensuring that all the forms were correctly filled. Cases of missing observation were easily traced and the teachers were able to re-evaluate any child whose response is incomplete.

80 of the students were randomly selected across the 5 schools to be assessed by the teacher and their assistant in order to assess the degrees of equivalence between appraisals inter-rater reliability with Spearman-Brown (Spearman, 1910 and Brown, 1910) value of 0.849 .

\section{RESULTS AND DISCUSSION}

SPSS (version 23.0 SPSS Inc.) and Stata 12.0 (StataCorp LP) were used for all descriptive analyses of items while lavaan package in R (Rosseel, 2012) was used for the confirmatory analysis. The confirmatory factor analysis for this research is based on MLE that assumes normality of the data. This is justified in this research by observing the univariate skewness and kurtosis. Based on the criteria set by Curran et al., (1996) for univariate normality, the obtained skewness and kurtosis are within the acceptable region for all the 30 items. Minimum values of skewness and kurtosis obtained for all the items are respectively -0.430 and -1.337 while the respective maximum values are 0.896 and 0.618 . 


\section{EXPLORATORY FACTOR ANALYSIS FOR THE SCBE-30}

\section{Sample Size}

What constitutes a good sample size in any structural modelling has been a major point of discussion. (Ding et al., 1995) suggest that when latent variables include many indications, a ratio of as few as 5 subjects per variable would be enough for normal and elliptical distributions, while a ratio of at least 10 subjects per variable would suffice for other distributions. In research on social competence evaluation, (Zupanic et al., 2000) uniformly sampled 100 kindergarten children aged from $2 \frac{1 / 2}{2}$ to $61 / 2$ years out of which 95 whose parental consent agreements were obtained from the parents were used for assessment. In the Portuguese validation, (Alejandro et al., 2016) involved 361 children (168 boys and 193 girls)aged 3 to 6 years from the greater Porto Area whose preschool teachers completed the SCBE-30. Sette et al., (2014) evaluated 414 students across schools in Italy. The original sample of 493 (241 boys and 252 girls) was reduced for both CFA and EFA because of missing values on the items of the SCBE scale. This study recruited 400 children but only 364 parental consent form was returned.

\section{Internal Consistency Test (Reliability)}

When variables produced from summated scales are employed as predictor components in objective models, reliability comes into play; it determines how well a test consistently assesses what it is designed to measure. Among the most widely reported tools for internal consistency is Cronbach's alpha developed by Cronbach (1951). Recent reviews however shown that there are better estimates of reliability (Sijtsma, 2008). Revelle \& Zinbarg (2009) also opposed using the glb (greatest lower bound) as the best estimates of reliability; they suggest using McDonald's $\omega_{t}$ (McDonald, 1999). In view of this, for this study, the internal consistency of the factors was observed using the psych package from CRAN (Revelle, 2008). The obtained estimates of reliability are 0.80 for Social Competence; 0.85 for Anxiety-Withdrawal; and 0.92 for Anger-Aggression. All these confirm the internal consistency of all items. (coefficient of 0.70 or higher is said to be "acceptable" in most social science research).

\section{Sex and Age}

Studies have shown that girls are more socially competent compared to boys while boys are more prone to externalizing behaviour (LaFreniere et al. 2002; LaFreniere \& Dumas, $1996^{\mathrm{b}}$ ). Report (LaFreniere et al., 2002) also revealed that pupils tend to be more socially competent as they grow older. In the original model of 3 factors with each having 10 items, table 2 shows the age and gender mean scores obtained for the evaluated children.

Table 2. Age and Gender mean scores for the 3 factors (each with 10 items)

\begin{tabular}{c||c|c|c||c|c|c||c|c|c}
\hline \hline \multicolumn{1}{l|}{} & \multicolumn{3}{|c||}{ Social Competence } & \multicolumn{3}{c|}{ Anxiety-Withdrawal } & \multicolumn{3}{c}{ Anger-Aggression } \\
\hline & Male & Female & Total & Male & Female & Total & Male & Female & Total \\
\hline 2 years & 3.545 & 3.691 & 3.633 & 3.164 & 3.382 & 3.295 & 3.550 & 3.045 & 3.247 \\
\hline 3 years & 3.531 & 3.687 & 3.598 & 2.690 & 3.204 & 2.912 & 2.915 & 2.855 & 2.889 \\
\hline 4 years & 3.542 & 3.703 & 3.623 & 2.903 & 3.043 & 2.974 & 2.660 & 2.407 & 2.532 \\
\hline 5 years & 3.581 & 4.239 & 3.983 & 2.843 & 2.991 & 2.933 & 2.771 & 1.930 & 2.257 \\
\hline \hline Total & $\mathbf{3 . 5 4 3}$ & $\mathbf{3 . 7 9 1}$ & $\mathbf{3 . 6 7 1}$ & $\mathbf{2 . 8 5 4}$ & $\mathbf{3 . 1 3 4}$ & $\mathbf{2 . 9 9 8}$ & $\mathbf{2 . 8 7 3}$ & $\mathbf{2 . 5 4 8}$ & $\mathbf{2 . 7 0 6}$ \\
\hline \hline
\end{tabular}


The social Competence of the evaluated children increases as their ages increases while both maladaptive behaviours reduce as the age reduces. Findings by (Dumas et al., 1998 and De Fruyt et al., 1998) are also supported by table 2. Female children score higher in Social Competence and Anxiety-Withdrawal (internalizing behaviour) but the males score higher in externalizing behaviour. This is in line with the claim by Puklel \& Gril (1999) that boys are more anxious with the manifestation of more behavioural negativities and less Prosocial when compared to girls. Social Competence has an average of above 3.50 while both internalizing and externalizing behaviours are averaged below 3.00.

With $\mathrm{P}$-value $=0.000$ and $\mathrm{F}_{\mathrm{cal}}=154.9549$, analysis of variance of the total mean score for the three factors shows that Social Competence (with overall mean $=3.671$ ) is significantly different from both maladaptive behaviours while both Anger-Aggression and Anxiety-Withdrawal are not significantly different.

\section{Inter-factor Correlations}

The inter-factor correlation for the orthogonal model (table 3) supports findings from different researches where correlations among the three factors of SCBE-30 had been reported in the literature (LaFreniere et al. 2002; Bigras \& Dessen, 2002; Sette et al., 2014). Social Competence (Prosocial) is negatively correlated with both AnxietyWithdrawal (internalizing behaviour) and Anger-Aggression (externalizing behaviour) while both Anger-Aggression and Anxiety-Withdrawal showed relative orthogonality.

Table 3. Inter-factor correlation coefficient (orthogonal model)

\begin{tabular}{l|l|l|l}
\hline \hline & Social Competence & Anxiety-Withdrawal & Anger-Aggression \\
\hline \hline Social Competence & 1 & & \\
\hline Anxiety-Withdrawal & $-0.440(0.000)$ & 1 & \\
\hline Anger-Aggression & $-0.601(0.000)$ & $0.441(0.000)$ & 1 \\
\hline \hline
\end{tabular}

\section{CONFIRMATORY FACTOR ANALYSIS FOR THE SCBE-30}

\section{Fit Indices}

Various model fit criteria and acceptable fit interpretation had been discussed (Browne \& Cudek, 1993). Absolute fit indices like $\chi^{2}$, GFI, SMRM, RMSEA are simply derived from the fit of the obtained/implied covariance matrix and MLE; they do not utilize alternative models for comparison. A $\chi^{2}$ value of 0 indicates a perfect fit or no difference in the sample covariance matrix and reproduced model-implied covariance matrix, (Schumacker \& Lomax, 1996). The goal of structural equation modelling is to achieve a chi-square value close to 0 . The Goodness of Fit index (GFI) value close to 0.90 reflect a good fit while the Root Mean Square Error of Approximation (RMSEA) and Standardized Root Mean Residual (SRMR) of value less than 0.05-0.08 implies a good model fit (Schumacker \& Lomax, 1996). This research compares fives models and compares various fit indices to confirm the best solution.

\section{The Models}

Five models are compared using diverse conditions for estimating factor loadings of the 30 items to the latent variables.

Model A (1 factor orthogonal model): Each model is assumed to be statistically independent i.e. a model is run for each factor (SC, AW, and AA). 
Model B (3 factors orthogonal model): The three factors are run together but with an assumption of 0 correlations among the factors.

Model C (3 factors oblique model): The three factors are assumed to be correlated

Model D (3 factors adjusted oblique model): Using measurement error covariance of modification index of above 5.00 as modification indices

Model E (3 factors adjusted oblique model): Fixing factor loadings of all non-significant parameters to 0 (i.e. removing all non-significant parameters from the model) and adjusting for modification indices of measurement error covariance with above 5.00 as modification indices

Measurement error covariance is used to modify the model rather than modifying the theoretical model in order to keep each of the three latent variables as a separate construct each with 10 observed variables.

The 10-item-subscale solution of the original SCBE-30 version was not confirmed by confirmatory factor analysis. A five-item subscale was discovered to be a better solution.

Table 4. Fit indices for the three models compared

\begin{tabular}{|c|c|c|c|c|c|c|c|}
\hline & Chi-Squaredf(P-value) & GFI & CFI & RMSEA & SRMR & Items with $\mathrm{FL}>0.4 \mathrm{D}$ & Items with Sig. FL \\
\hline Model A & 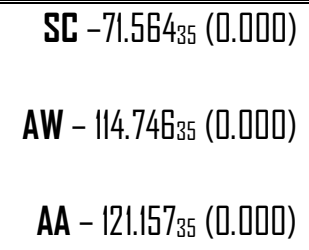 & $\begin{array}{l}0.964 \\
0.944 \\
0.937\end{array}$ & $\begin{array}{l}0.795 \\
0.684 \\
0.788\end{array}$ & $\begin{array}{l}0.054 \\
0.079 \\
0.082\end{array}$ & $\begin{array}{l}0.053 \\
0.064 \\
0.064\end{array}$ & $\begin{array}{l}\text { SC-18, 20, 25, } 27 \\
\text { AW-6, 8, 9, 10 } \\
\text { AA-3, 4, 5, 12, 17 }\end{array}$ & $\begin{array}{l}\text { I6, 18, 20, 22, 24, 25, 27, 2 } \\
\text { 2, 6, 8, ४, 10, 15, 21 } \\
\text { 3,4,5,11,12,17,19,26,29,30 }\end{array}$ \\
\hline Model B & $1100.759_{405}(0.000)$ & 0.826 & 0.477 & 0.069 & 0.093 & $\begin{array}{l}\text { SC-18, 20, 25, } 27 \\
\text { AW-6, 8, 9, 10 } \\
\text { AA-3, 4, 5, 12, } 17\end{array}$ & $\begin{array}{l}\text { 18, 20, 22, 24, 25, 27, } 28 \\
\text { 2, 6, 8, ४, 10, 15, 21 } \\
\text { 3,4,5,11,12,17,19,26,29,30 }\end{array}$ \\
\hline Model [ & $1004.803402(0.000)$ & 0.838 & 0.547 & 0.064 & 0.073 & $\begin{array}{l}\text { SC-18, 20, 22, 25, 27 } \\
\text { AW-6, 8, 马, 10 } \\
\text { AA-3, 4, 5, 12, 17, 26, } 29\end{array}$ & $\begin{array}{l}\text { 18, 20, 22, 24, 25, 27, } 28 \\
\text { 2, 6, 8, ४, 10, 15, } 21 \\
\text { 3,4,5,11,12,17,19,26,29,30 }\end{array}$ \\
\hline Model D & 490.986348([.000) & 0.921 & 0.893 & 0.034 & 0.052 & $\begin{array}{l}\text { SC-18, 20, 25, 27 } \\
\text { AW-6, 8 } \\
\text { AA- 4, 5, 12, 17, 26, } 30\end{array}$ & $\begin{array}{l}\text { 18, 20, 22, 24, 25, 27, } 28 \\
\text { 2, 6, 8, 9, 10, 15, 21 } \\
\text { 3,4,5,11,12,17,19,26,29,30 }\end{array}$ \\
\hline Model E & 261.316208(0.007) & 0.946 & 0.953 & 0.027 & 0.047 & $\begin{array}{l}\text { SC- 18, 20, 25, } 27 \\
\text { AW- 2, 6, 8 } \\
\text { AA- 4, 5, 12, 17, 26, } 30\end{array}$ & $\begin{array}{l}\text { 18, 20, 22, 24, 25, 27, } 28 \\
\text { 2, 6, 8, ४, 10, 15, 21 } \\
\text { 3,4,5,11,12,17,19,26,29,30 }\end{array}$ \\
\hline
\end{tabular}




\section{Factor Loading}

What constitutes an acceptable factor loading (standardized coefficients) have been an issue in structural equation modelling. For example, LaFreniere et al. (2002) and LaFreniere \& Dumas, $\left(1996^{\mathrm{b}}\right)$ laid emphasis on factor loading greater than 0.40 while Sette et al., (2014) and Alejandro et al. (2016) reported for factor loading of 0.50 and above. This study however focuses on the significant contribution of each standardized coefficient (factor loading) on each Item using the P-value at a 5\% level.

An inference that can be drawn from Table 4 is that the SCBE-30 has designed by LaFrenière \& Dumas $\left(1996^{\mathrm{b}}\right)$ has some psychometric limitations in the Nigerian context. Observing the significant contribution of items to each latent variable reveal that the Social Competence factor has 7 items (items 18, 20, 22, 24, 25, 27, and 28), Anxiety-Withdrawal also has 7 items (items 2, 6, 8, 9, 10, 15, 21) while Anger-Aggression has all its 10 items (items 3, 4, 5, 11, 12, 17, 19, 26, 29, 30) to be significant.

Considering factor loading of 0.40 and above as reported by LaFreniere et al. (2002) and LaFreniere and Dumas, $\left(1996^{\mathrm{b}}\right)$, Social Competence has 4 items $(18,20,25$ and 27) that loaded on the final model, Anxiety-Withdrawal has 3 items (2, 6, and 8) while AngerAggression has 6 items (4, 5, 12, 17, 26 and 30)

The inter-factor correlations for the final model (Model E) are presented in table 5.

Table 5. Inter-factor correlation coefficient (Oblique model with adjusted modification indices using measurement error covariance)

\begin{tabular}{l|l|l|l}
\hline \hline & Social Competence & Anxiety-Withdrawal & Anger-Aggression \\
\hline \hline Social Competence & 1 & & \\
\hline Anxiety-Withdrawal & $-0.418(0.0000)$ & 1 & \\
\hline Anger-Aggression & $-0.610(0.0000)$ & $0.421(0.0000)$ & 1 \\
\hline \hline
\end{tabular}

\section{Discussion}

This study attempts to confirm the 3-factor structure of the SCBE-30 in a Nigerian sample of pre-schoolers (nursery and kindergarten). The significant contribution of the items on each latent variable as well as factor loading of 0.40 or more are considered against the standard 10-item per subscale solution suggested by LaFrenière \& Dumas $\left(1996^{\mathrm{b}}\right)$. The study utilized both EFA and CFA approach on the 3-factor model that proved to be valid for the Nigerian sample. Various compared fit indices (table 4) indicate that the 3-factor subscale obtained gave more acceptable reliability than the standard SCBE-30.

The result shows that item 18 (Cooperates with other children), item 20 (Comforts or assists another child in difficulty), item 25 (Shares toys and other personal materials with other children), and item 27 (Helps with everyday tasks) showed factor loading of above 0.40. Only 3 items (item 2-Tired, item 6-Worries and item 8-Timid, afraid) showed factor loading of above 0.40 for Anxiety-Withdrawal. The 6 items that showed factor loading of 0.40 and above for Anger-Aggression are item 4-Gets angry when interrupted; item 5Irritable gets mad easily; item 12-Forces other children to do things they don't want to do; item 17- Hits, bites or kicks other children; item 26-Hits teacher or destroys things when angry with the teacher; and item 30- Defiant when reprimanded. (Costello \& Osborne, 2005) indicated that items can be dropped from the model because the priori factor model could have been flawed or poorly written. In their analysis, (Sette et al., 2014) finally concluded with 7 items for Social Competence, 6 items for Anger-Aggression and 8 Items for Anxiety-Withdrawal while (Alejandro et al., 2016) had 5 items per factor in their final 
model. A shorter/abridged version of SCBE has an advantage since it requires a shorter time for filling by the teachers who are mostly occupied with their daily activities. (Butovskaya \& Demianovitsch, 2002) had suggested that test length does not ensure psychometric superiority.

\section{CONCLUSION}

With the highest total item average (3.671), the sampled show more social competence than other factors compared which increases as the evaluated children's ages increases. Female pupils show more social competence and anxiety withdrawal than males. Male preschoolers however are more prone to AA related attitudes. In view of this, caregivers/teachers/parents must understand that social incompetence occur alongside other difficulties, hence interventions should be targeted to groups rather than individuals

Special attention is expected to be given to children who show various AngerAggression factors. They can be taught on being effective during group discussion and a fair player like following rules and taking turns. Anger management and conflict resolution skills may also be imbibed in aggression-prone children (Coplan et al., 2004).

Studies had shown that Parental income and educational status have a significant effect on children's performance (Bigras \& Dessen, 2002). Hence, schools are advised to request such information at the admission point in Nigerian schools. This will ensure that proper attention is given to all deserving children in schools.

\section{REFERENCES}

Alejandro, V.E., Tânia, R., Joana, C.L., Pedro, T. \&Orlanda, C. (2016). Portuguese validation of the Social Competence and Behaviour Evaluation Scale (SCBE-30), Psicologia: Reflexão e Crítica 29:22 DOI 10.1186/s41155-016-0014-z

Bigras, M. \&Dessen, M.A. (2002). Social Competence and Behavior Evaluation in Brazilian preschoolers. Early Educ Dev., 13:139-51. doi:10.1207/s15566935eed1302_2

Blandon, A. Y., Calkins, S. D., Grimm, K. J., Keane, S. P., \& O’Brien, M. (2010). Testing a developmental cascade model of emotional and social competence and early peer acceptance. Development and Psychopathology, 22, 737-748. doi: $10.1017 /$ S0954579410000428

Bollen, K.A. (1989). Structural equations with latent variables. Oxford, England: Wiley.

Brown, W. (1910). Some experimental results in the correlation of mental abilities. British Journal of Psychology, 3, 296-322

Browne, M.W., \&Cudeck, R. (1993). Alternative ways of assessing model fit. In K. A. Bollen\& J. S. Long (Eds.), Testing structural equation models (pp. 136-162). Newbury Park, CA: Sage.

Butovskaya, M. L., \&Demianovitsch, A. N. (2002). Social competence and behavior evaluation (SCBE-30) and socialization values (SVQ): Russian children ages 3 to 6 years. Early Education \& Development, 13, 153-170. doi:10.1207=s15566935eed1302 3

Coplan, Robert J., Leanne C. Findlay, and Larry J. Nelson (2004). "Characteristics of Preschoolers with Lower Perceived Competence." Journal of Abnormal Child Psychology 32 (August 2004): 399-409.

Costello, A. B., \& Osborne, J. W. (2005). Best practices in exploratory factor analysis: Four recommendations for getting the most from your analysis. Practical Assessment, Research and Evaluation, 10, 173-178.

Crick, N.R. \& Dodge, K.A. (1994)."A review and reformulation of social informationprocessing mechanisms in children's social adjustment".Psychological Bulletin. 115: 74-101. doi:10.1037/0033-2909.115.1.74. 
Curran, P. J., West, S. G., \& Finch, J. F. (1996). The robustness of test statistics to nonnormality and specification error in confirmatory factor analysis. Psychological Methods, 1, 16-29. doi:10.1037=1082-989X.1.1.16

Cronbach, L.J. (1951). "Coefficient alpha and the internal structure of tests". Psychometrika. 16 (3): 297-334. doi:10.1007/bf02310555.

De Fruyt, F., van Hiel, A. \& Buyst, V. (1998). Parental personality descriptions of boys and girls. In G.A. Kohnstamm, C.F. Jr. Halverson, I. Mervielde\& V. Havill (Eds.), Parental descriptions of child personality: Development antecendental of the Big Five? (pp. 155-167). Mahwah, NJ: Erlbaum.

Dodge, K.A.; Asher, S.R. \& Parkhurst, J.T. (1989). C. Ames \& R. Ames, ed. Research on Motivation in Education. San Diego, CA: Academic Press, Inc.

Ding, L., Velicer, W. F., \& Harlow, L. L. (1995). Effects of estimation methods, number of indicators per factor, and improper solutions on structural equation modeling fit indices. Structural Equation Modeling: A Multidisciplinary Journal, 2, 119-143

Dumas, J.E., LaFreniere, P.J., Capuano, F., \&Durning, P. (1997).Manuel Francais du ProfilSociao-Affectif. Paris, France: Les Editions du Centre de PsychologieAppliquée.

Dumas, J.E., Martinez, A., \&LaFreniere, P.J. (1998). The Spanish version of the Social Competence and Behavior Evaluation: Translation and field testing. Hispanic Journal of Behavioural Development, 20(2), 255-269.

Hartup, W. W. (1992). Having friends, making friends, and keeping friends: Relationships as educational contexts. ERIC Digest. Champaign, IL: ERIC Clearinghouse on Elementary and Early Childhood Education.

Lavigne, J.V., Gibbons, R.D., Arend, R., Rosenbaum, D., Binns, H. J., \&Christoffel, K. K. (1999). Toward rational service planning in pediatric primary care: continuity and change in the occurrence of psychologically among children enrolled in pediatric practices. Journal of Pediatric Psychology, 24(5), 393-403.

LaFreniere, P.J. \& Dumas, J.E. (1996)a. Social Competence and Behavior Evaluation, Preschool Edition (SCBE), Los Angeles, Western Psychological Services.

LaFreniere, P.J., \& Dumas, J.E. (1996)b. Social competence and behavior evaluation in children ages 3 to 6 years: The short form (SCBE-30). Psychological Assessment, 8, 369-377. doi:10.1037=1040-3590.8.4.369

LaFreniere, P.J., Dumas, J., Dubeau, D., Capuano, F. (1992).The development and validation of the preschool socio-affective profile.Psychol Assess $\mathrm{J}$ Consult Clin Psychol. 1992;4:442-50. doi:10.1037/1040-3590.4.4.442

LaFreniere, P.J., Masataka, N., Butovskaya, M., Chen, Q., Dessen, M. A., Atwanger, K., Schreiner, S., Montirosso, R., \&Frigerio, A. (2002). Cross-cultural analysis of Social Competence and Behavior Problems in Preschoolers. Early Education \& Development, 13(2), 201-219.

McDonald, R.P. (1999). Test theory: A unified treatment. Hillsdale: Erlbaum

Malti, T. (2006).Aggression, self-understanding, and social competence in Swiss elementary-school children. Swiss Journal of Psychology, 65, 81-91. doi:10.1024=1421-0185.65.2.81

Poissant, H. (2000). Quelques axes de recherché pour uneétude multi-factorielle du trouble déficitaire de l'attention avec ou sans hyperactivité. Revue Canadienne de Psychoéducation, 29(2), 143-153

Puklel, M. \&Gril, A. (1999).Human Development. New York: McGraw-Hil Inc.

Revelle, W. (2008). psych: Procedures for personality and psychological research (R package version 1.0-51). 
Revelle, W. \& Zinbarg, R. E. (2009). Coefficient Alpha, Beta,Omega, and the GLB: Comments on Sijtsma, Psychometrika, 74(1): 145-154.

Richardson, L.A., Keller, A.M., Selby-Harrington, M.L., \& Parrish, R.C. (1996). Identification and treatment of children's mental health problems by primary care providers: A critical review of research. Archives of Psychiatric Nursing, 10(5), 293303

Schumacker, R.E. \& Lomax, R.G. (1996): A Beginner's Guide to Structural Equation Modeling, Lawrence Erlbaum, pp. 75-76, (0-8058 - 1766-2).

Semrud-Clikeman, M. (2007).Social competence in children. New York, NY: Springer Science Business Media.

Sette, S., Baumgartner, E. \& MacKinnon, D.P. (2014). Assessing Social Competence and Behavior Problems in a Sample of Italian Preschoolers Using the Social Competence and Behavior Evaluation Scale, Early Education and Development, 0: 1-20 ISSN: 1040-9289 print/1556-6935 online DOI: 10.1080/10409289.2014.941259

Sijtsma, K. (2008). On the use, the misuse, and the very limited usefulness of Cronbach's alpha. Psychometrika.

Spearman, C.C. (1910). Correlation calculated from faulty data. British Journal of Psychology, 3, 271-295.

Voeller, K.K.S. (1994). G.R. Lyon, ed. Frames of reference for the assessment of learning disabilities: New views on measurement issues. Baltimore: Paul H. Brookes Publishing Company. pp. 523-54.

Yves Rosseel (2012). lavaan: An R Package for Structural Equation Modeling. Journal of Statistical Software, 48(2), 1-36. URL http://www.jstatsoft.org/v48/i02/

Zupanic, M., Gril, A. \& Kavcic, T. (2000). The Slovenian version of the Social Competence and Behaviour Evaluation Scale - Preschool Edition (OLSP): the second preliminary validation. Psiholoskaobzorja/Horizons of Psychology, 9(4), 7-23 